\title{
UMBATRA
}

Indonesian Journal of Anthropology

Volume 5 (1) Juli 2020 || eISSN 2528-1569 | pISSN 2528-2115 || http://jurnal.unpad.ac.id/umbara

DOI : 10.24198/umbara.v5i1.28268

\section{Perubahan Peran Seniman dalam Dinamika Ruang Publik di Taman Ismail Marzuki (1968-2018)}

\author{
Niken Flora Rinjani \\ Program Studi Sarjana Antropologi, FISIP, Universitas Padjadjaran \\ nikenflorarinjani@gmail.com
}

\begin{abstract}
This paper shows how physical reconstructions and managerial development of the Jakarta Arts Center -Taman Ismail Marzuki (PKJ-TIM), have changed the role of artists at that arts center. TIM which has been established for 50 years is the largest arts center in Jakarta, and eventually became a hub for national and international artistic exchanges. This study uses a conceptual framework relating the locality to supralocal structures, to see TIM as a public space as well as a social space that form the sense of place among the artists. The research method used is ethnography. Data was collected through participant-observation, in-depth interviews, literature reviews, and documentation. The study found that social relationships between artists and their peers inside and outside of TIM, the TIM management, the public at TIM and with the physical environment of TIM, create a sense of place for artists. There are differences in the role of TIM artists in the past (during the reign of DKI Jakarta Governor Ali Sadikin) and at present, following subsequent shifts of DKI Jakarta administration. The place has undergone several restorations. The role of artists in TIM has been slowly reduced from being active actors and managers of art activities at TIM, to only being art performers. The changes have decreased the artists' interest of TIM as a center for their artistic enterprise. In the artists' language, TIM has become a place for art activities that lose the spirit of artistry. In conclusion, changes in the artists' role at the TIM is related to the wider structure, namely the Provincial Government of DKI Jakarta, and their relations with fellow artist and arts institutions at the local, national, and even international level.
\end{abstract}

Keywords: Taman Ismail Marzuki, artists, the role of artists, management of the arts center, government

\begin{abstract}
Abstrak
Tulisan ini memperlihatkan bagaimana perubahan fisik dan pengelolaan Pusat Kesenian Jakarta - Taman Ismail Marzuki (PKJ-TIM) telah mengubah peranan para seniman di pusat kesenian tersebut. TIM yang telah berdiri selama 50 tahun merupakan pusat kesenian terbesar di Jakarta, yang telah menjadi simpul pertukaran kesenian di lingkup nasional dan internasional. Kajian ini menggunakan kerangka konseptual yang mengaitkan lokalitas dan struktur supralokal, untuk melihat TIM sebagai ruang publik dan ruang sosial yang bisa membentuk perasaan para seniman akan tempat itu (sense of place). Metode penelitian yang digunakan adalah etnografi, dan data dikumpulkan melalui pengamatan terlibat, wawancara men-
\end{abstract}


dalam, studi pustaka, dan dokumentasi. Studi ini menemukan bahwa di TIM yang merupakan ruang publik sekaligus ruang sosial bagi para senimannya, hubungan-hubungan sosial di antara para seniman dengan sesamanya di dalam maupun di luar TIM, dengan pengelola TIM, dengan publik di TIM, serta hubungan antara seniman dengan lingkungan fisik TIM, menciptakan perasaan kuat para seniman akan tempat itu (sense of place). Ditemukan perbedaan di antara peran seniman di TIM pada masa lalu (masa pemerintahan Gubernur DKI Jakarta Ali Sadikin) dan dewasa ini, seiring dengan penggantian pemerintahan DKI Jakarta setelahnya. TIM telah mengalami banyak perubahan fisik. Peranan seniman di TIM perlahan berkurang, dari semula sebagai pelaku dan pengelola aktif kegiatan seni di TIM menjadi terbatas hanya sebagai pelaku seni saja. Perubahan ini mengendurkan rasa keterikatan seniman pada TIM sebagai tempat pusat berkesenian. Dalam bahasa seniman, TIM menjadi tempat kegiatan seni yang kehilangan roh kesenimanan. Kesimpulannya, perubahan peranan seniman di TIM sebagai pusat seni, terkait dengan struktur yang lebih luas, yakni Pemerintah Provinsi DKI Jakarta, dan hubungan mereka dengan sesama seniman dan lembaga-lembaga kesenian lain di tingkat lokal, nasional, bahkan internasional.

Kata kunci : Taman Ismail Marzuki, peranan seniman, pengelolaan Pusat Kesenian Jakarta, Pemerintah Daerah, sense of place

\section{Pendahuluan}

Pusat Kesenian Jakarta Taman Ismail Marzuki (selanjutnya disingkat PKJ-TIM) merupakan pusat kesenian terbesar di Jakarta. PKJ-TIM didirikan oleh Gubernur DKI Jakarta Ali Sadikin pada tahun 1968. TIM yang letaknya di kawasan Jakarta Pusat ini menempati lahan seluas sekitar delapan hektar. Nama Ismail Marzuki diberikan sebagai penghargaan dan penghormatan kepada salah satu penyair dan komponis Indonesia atas jasa-jasanya kepada bangsa dan negara (Leirissa, 1994).

Ali Sadikin tergerak untuk mendirikan pusat kesenian di Jakarta karena setiap kota besar yang dia kunjungi mempunyai pusat kesenian. Rencana membangun pusat kesenian tersebut ia sampaikan ketika peresmian kembali Balai Budaya di awal tahun 1968. Ia menyadari bahwa tempat tersebut terlalu kecil untuk menampung kegiatan kesenian hingga akhirnya ditemukan tempat strategis bekas kebun binatang di Cikini (Yusra, 1994).

Di pihak seniman, pusat kesenian di ibu kota sudah lama diimpikan sejak tahun 1950-an. Impian tersebut tidak dapat terlaksana karena dua alasan. Pertama, para seniman Jakar- ta yang biasa berkumpul di Pasar Senen atau Balai Budaya terpecah belah karena arus perpecahan partai politik. Perpecahan tersebut dimulai pada waktu kampanye pemilihan umum tahun 1955 dan memuncak pada periode Orde Lama. Kedua, pada masa itu, pemerintahan tidak memiliki dana dan perhatian yang cukup pada kesenian (Yusra, 1994).

Gagasan pendirian pusat kesenian dipelopori oleh tiga orang seniman, Ilen Surianegara, Ajip Rosidi, dan Ramadhan K.H. Mereka membawa rencana sebuah gelanggang kesenian yang dahulu pernah dibuat oleh Oesman Effendi untuk disampaikan kepada Bang Ali (Rosidi, 2006), dan mendapatkan sambutan baik. Impian tersebut akhirnya terwujud pada peresmian TIM tanggal 10 November 1968, dengan penyelenggaraan acara seni besar-besaran selama tujuh hari (Yusra, 1994).

Ketika TIM mulai bekerja, Gubernur Ali Sadikin menyerahkan pengelolaan TIM kepada seniman tanpa campur tangan pemerintah. Di antara TIM dengan struktur supralokal ${ }^{1}$, yakni Pemerintah Provinsi DKI Jakarta terjalin kerja sama yang baik. Kepercayaan yang diberikan pemerintah saat itu membuat seniman leluasa

\footnotetext{
${ }^{1}$ Struktur supralokal adalah badan sosial yang prinsip organisasinya independen, tidak harus sesuai dengan kondisi lokal dan ekologis tertentu. (Leeds, 1973).
} 
untuk berkegiatan di sana sekaligus mengelola TIM.

TIM sebagai pusat kesenian memiliki masa gemilang pada tahun 1970-an hingga tahun 1980-an. Namun seiring berjalannya waktu, TIM mengalami perkembangan dan perubahan dari segi pengelolaan dan keadaan fisik sehingga ikut memengaruhi kedudukan seniman di TIM. Eksistensi TIM pun mulai meredup dengan munculnya ruang-ruang publik lain yang didirikan oleh pemerintah, swasta, individu maupun komunitas, seperti galeri seni (Dewi, 2017). Perkembangan tersebut memberikan alternatif ruang-ruang baru bagi seniman dalam berkarya.

Ruang publik adalah ruang milik bersama yang digunakan warga masyarakat untuk melakukan aktivitasnya dalam kehidupan sehari-hari ataupun berkala secara pribadi maupun berkelompok (Carr, Francis, Rivlin, dan Stone, 1992). TIM sebagai ruang publik digunakan oleh berbagai kalangan, mulai dari mahasiswa, seniman, hingga masyarakat umum dengan kebutuhan yang berbeda-beda. Penelitian ini dilakukan untuk mengetahui pengaruh perubahan fisik dan pengelolaan TIM sebagai ruang publik terhadap sense of place (rasa akan tempat) di kalangan pengguna utama TIM, yaitu seniman.

Penelitian oleh Farihah (2014) menjelaskan secara historis perkembangan PKJ-TIM selama 30 tahun berdiri dengan adanya berbagai masalah dan tantangan. Farihah menemukan bahwa PKJ-TIM berhasil menjadi oase kesenian untuk masyarakat di tengah kekuasaan Orde Baru yang cenderung menekan. Adapun penelitian saya, selain membahas perkembangan PKJ-TIM sejak berdirinya 50 tahun silam, juga berfokus pada sisi pengguna TIM, yakni seniman.

\section{Kajian Pustaka}

\section{Lokalitas dan Struktur Supralokal}

Sebuah kota akan senantiasa mengalami berbagai permasalahan dalam perkembangannya, baik yang terkait dengan lingkungan fisik maupun ekonomi, hukum, hingga kehidupan sosial dan budaya perkotaan (Manurung, 2018). Oleh karenanya, studi tentang kota, khususnya mengenai perancangan dan penataan kota selalu menarik. Jakarta sebagai kota unggul (primate city) dengan kompleksitasnya merupakan pusat segalanya di tingkat nasional. Jakarta, secara simbolis diciptakan sebagai pusat budaya, identitas nasional, dan kekuasaan yang patut dicontoh (Nas, 2011). Kajian tentang kota dapat difokuskan ke suatu lokalitas di dalam kota.

Lokalitas, menurut Leeds (1973), adalah suatu tempat atau wilayah yang dapat ditengarai secara inderawi, dengan sumber daya seperti bangunan dan populasi (tenaga kerja) yang relatif ajeg. Lokalitas sebagai lokus atau tempat interaksi warga, memiliki simpul-simpul jaringan interaksi yang padat dari berbagai jenis hubungan. Berbeda dengan konsep komunitas yang menekankan hubungan yang bersifat personal, lokalitas juga memiliki hubungan yang impersonal dan sekunder (Leeds, 1973).

Lokalitas hampir selalu ditandai dengan kemampuan untuk berhubungan dengan lembaga eksternal secara mandiri (Leeds, 1973). Kemandirian tersebut dibentuk dan dikelola oleh bermacam-macam hubungan sosial di lokalitas tersebut, juga disesuaikan dengan keberadaan institusi supralokal.

Secara umum, evolusi komunitas melibatkan penyesuaian yang berkelanjutan antara lokalitas dan institusi kekuatan supralokal (Leeds, 1973). Struktur supralokal adalah badan sosial yang prinsip organisasinya independen karena tidak sesuai dengan kondisi lokal dan ekologis tertentu. Sementara itu, institusi supralokal mengacu pada prinsip dan cara operasi struktur supralokal (Leeds, 1973). TIM sebagai lokalitas dikontrol oleh struktur supralokal, dalam hal ini adalah Pemerintah Provinsi DKI Jakarta melalui institusi supralokal yang mengelola TIM.

\section{Ruang Publik}

Ruang publik adalah ruang pertemuan yang luas dan sebagian besar tidak direncanakan (Scruton, 1987). Meskipun tampaknya ruang publik dibangun untuk keperluan interaksi 
antarmanusia, namun menurut Scruton, kebanyakan pertemuan dan interaksi yang terjadi di sana mungkin tidak direncanakan. Oleh karena itu, maka sebuah ruang publik seharusnya tidak terlalu banyak peraturan.

Demi tercapainya suatu kota yang dapat berkembang sesuai perencanaan, maka diperlukan ruang-ruang untuk menunjang suatu kawasan, di antaranya ruang publik yang dapat menyempurnakan ruang kota tersebut (Kustianingrum, Sukarya, Nugraha, dan Tyagarga, 2013).

Penanganan ruang publik pun perlu berkesinambungan sebagai upaya dalam meningkatkan kualitas untuk mewadahi keinginan warga kota. Di dalam perancangan kota, ruang publik menjadi salah satu bagian penting karena di situ terjadi berbagai aktivitas masyarakat dan tersedia berbagai fasilitas kota (Manurung, 2018). Oleh karena itu, untuk mencapai keseimbangan di suatu kota, diperlukan ruang publik yang dirancang dan ditata dengan baik sebagai representasi berbagai aktivitas publik.

Terdapat empat karakter pada ruang publik. Pertama, ruang tempat masyarakat berinteraksi, meliputi interaksi sosial, ekonomi dan budaya, dengan penekanan utama pada terjadinya beragam aktivitas. Kedua, ruang yang diadakan, dikelola dan dikontrol secara bersama, baik oleh instansi publik atau privat untuk kebutuhan dan kepentingan publik. Ketiga, ruang yang terbuka dan dapat diakses oleh semua orang, baik secara visual maupun secara fisik. Terakhir, ruang untuk masyarakat agar dapat bebas beraktivitas (Sunaryo, Soewarno, Ikaputra, dan Setiawan, 2010).

Setiap orang dapat memposisikan ruang publik sebagai ruang seni. Hal ini dapat terjadi ketika mereka merespon karya atau pertunjukan seni. Namun, pemahaman mereka mengenai ruang publik tersebut tidak berubah. Ruang publik didasarkan pada interaksi yang terjadi di dalamnya. Melalui interaksi itulah, seseorang dapat merasakan pengalaman yang berbeda (Raditya, 2016).

\section{Sense of Place}

Secara sosial, ruang kota diproduksi dan dibangun melalui pengalaman dan interaksi sosial (Low, 1996). Ruang publik sebagai ruang sosial akan menumbuhkan rasa akan tempat (sense of place). Shamai (1991) menjelaskan bahwa suatu tempat bukan hanya sebuah objek, melainkan bagian lebih besar yang dirasakan melalui pengalaman dan peristiwa yang berarti. Sense of place adalah hubungan emosional yang terjalin antara orang dan tempat yang dapat dipengaruhi oleh nilai, keyakinan, dan perilaku kolektif. Selain itu, sense of place tidak hanya berkembang dari pengalaman pribadi, melainkan pengalaman kolektif melalui hubungan jangka panjang (Najafi dan Shariff, 2011). Tuan (1977) berpendapat bahwa sense of place juga dapat tercipta dengan cepat, seperti cinta pada pandangan pertama (Najafi dan Shariff, 2011).

Gussow membagi sense of place menjadi tiga tingkat. Tingkat pertama, orang melakukan aktivitas di suatu tempat, namun belum memiliki keterikatan akan tempat tersebut. Tingkat kedua, keakraban yang biasa. Tingkat ketiga, menunjukkan keakraban dan keterlibatan mendalam seseorang pada suatu tempat. Pada tingkat ini, orang-orang di dalamnya mulai memiliki partisipasi yang dalam dan kuat. Tingkat ketiga, keakraban yang mendalam dengan tempat dan melibatkan "existential insideness" seseorang. Existential insideness adalah perasaan paling kuat dari pengalaman orang akan tempat ketika mereka berada di komunitas atau "rumah" mereka sendiri (Relph, 1976).

Konsep sense of place menuntut peneliti untuk memperhatikan konsep-konsep emik tentang rasa keterikatan orang terhadap tempat. Melalui konsep sense of place, peneliti mencari tahu pengetahuan dan pengalaman seniman, serta harapan dan ikatan emosional mereka terhadap TIM.

\section{Metode}

Penelitian ini dilakukan dengan metode etnografi. Pengumpulan, analisis, dan penyajian data dengan metode etnografi membantu peneli- 
ti menggali informasi yang mendalam serta mengangkat pemahaman emik mengenai makna perubahan TIM oleh seniman yang mengenal TIM. Teknik pengumpulan data meliputi pengamatan terlibat, wawancara mendalam, studi pustaka, dan dokumentasi. Pengamatan terlibat dilakukan untuk mengamati aktivitas pengguna di TIM. Wawancara mendalam dilakukan untuk mendapatkan data primer tentang pengalaman seniman di TIM, juga untuk triangulasi dan menambah data dari proses observasi. Wawancara dilakukan menggunakan pedoman wawancara dengan pertanyaan terbuka pada sejumlah informan yang diperoleh melalui proses snowball melalui rekomendasi informan pangkal sehingga mempermudah peneliti untuk mendapatkan informan yang tepat. Kategori informan dalam penelitian ini adalah seniman, karyawan PKJ-TIM, karyawan BP, dan karyawan UP. Di dalam tulisan ini, digunakan nama samaran untuk informan seniman. Seniman yang menjadi informan adalah Joni (64 tahun) dan Gatot (65 tahun) di bidang teater, Agung (61 tahun) di bidang seni rupa, Gerry (64 tahun) di bidang film, Ninis (60 tahun) di bidang tari, dan Eka (66 tahun) di bidang seni musik.

Selain itu, sumber data sekunder, yaitu pustaka dan dokumen dimanfaatkan sebagai pelengkap data primer. Sumber data sekunder dalam penelitian ini adalah dokumen mengenai TIM dalam bentuk arsip, foto, buku, dan lain-lain juga berita dari media cetak dan media daring. Untuk mengikuti perkembangan mutakhir yang berlangsung cepat dan datanya sukar didapat dari penelitian lapangan, peneliti mengandalkan informasi dari media daring.

\section{Hasil dan Pembahasan}

\section{Pengelolaan Taman Ismail Marzuki}

TIM mengalami dinamika pengelolaan dari awal berdirinya hingga sekarang. Lembaga-lembaga yang masih berdiri hingga sekarang adalah Dewan Kesenian Jakarta (DKJ), Akademi Jakarta (AJ), dan Institut Kesenian Jakarta (IKJ).

Dewan Kesenian Jakarta yang sebelumnya bernama Badan Pembina Kebudayaan (BPK) merupakan lembaga yang dibentuk oleh seniman. Lembaga ini dikukuhkan oleh Gubernur Ali Sadikin pada tanggal 7 Juni 1968. Kedudukan DKJ adalah lembaga seniman yang mewakili seluruh komunitas seniman di Jakarta dari berbagai bidang seni termasuk seni tradisional. DKJ yang anggotanya berjumlah 25 orang terdiri dari enam komite, yakni Komite Film, Komite Sastra, Komite Teater, Komite Musik, Komite Seni Rupa, dan Komite Tari (Peraturan Gubernur Provinsi DKI Jakarta Nomor 64, 2006).

Akademi Jakarta (AJ) diresmikan tanggal 24 Agustus 1970. Lembaga ini merupakan dewan kehormatan bagi seniman dan budayawan yang anggotanya pertama kali dipilih oleh Dewan Kesenian Jakarta. Namun, untuk selanjutnya AJ memilih anggotanya sendiri. Pembentukan AJ awalnya bertujuan agar regenerasi anggota DKJ adalah seniman, bukan birokrat yang tidak mengerti kesenian (Rosidi, 2006). Selain memilih anggota DKJ, Akademi Jakarta bertugas sebagai Dewan Penasihat bagi Gubernur DKI Jakarta pada bidang seni dan budaya (Alisjahbana et al., 1993).

Pada tahun 1970, Ali Sadikin membentuk wadah bernama Lembaga Pendidikan Kesenian Jakarta (LPKJ) untuk menciptakan caloncalon seniman bermutu, serta untuk pengembangan sarana dan prasarana pusat kesenian. Ali Sadikin menginginkan agar keragaman kreasi dan ekspresi seni dapat dinikmati masyarakat Jakarta dan tamu dari negara asing (Yudoseputro, 1994). Bangunan IKJ dibangun di dalam kompleks TIM agar mahasiswa LPKJ akrab dengan pertunjukan dan pameran yang ada di TIM (Hadimadja, 1992). Di tahun tersebut pengelolaan Lembaga Pendidikan Kesenian Jakarta berada di bawah Dewan Kesenian Jakarta. Jadi, DKJ memegang dua proyek utama, yaitu PKJ-TIM dan LPKJ. LPKJ kemudian diresmikan oleh Presiden Soeharto pada tahun 1976. Pada tahun 1985, Lembaga Pendidikan Kesenian Jakarta berganti nama menjadi Institut Kesenian Jakarta (IKJ) supaya dapat menyelenggarakan program pendidikan kesarjanaan. Kampus IKJ memiliki luas 1,6 ha dan meliputi lima disiplin seni, yaitu tari, teater, musik, 
seni rupa, dan film. Pendidikan lima disiplin seni tersebut dihimpun dalam tiga fakultas yang telah disahkan Departemen Pendidikan dan Kebudayaan (Depdikbud) pada tahun 1987 (Yudoseputro, 1994). Di kemudian hari, pengelolaan IKJ diserahkan kepada Yayasan Seni Budaya Jakarta (Keputusan Gubernur Provinsi DKI Jakarta Nomor 790, 2013). Saat ini, IKJ berada di bawah naungan Departemen Pendidikan dan Kebudayaan.

TIM dan LPKJ pada awalnya merupakan proyek utama DKJ. Pada tahun 1968-1980, TIM mencapai masa kejayaannya. Pemerintah mendanai dan menyediakan fasilitas untuk program-program yang diadakan lembaga kesenian sehingga menumbuhkan inovasi kreatif masyarakat dalam seni klasik maupun modern (Hatley, 1994). Dalam kebijakan kebudayaan Pemerintah DKI, PKJ-TIM berada di prioritas utama, dibuktikan dengan pemberian dana yang cukup untuk PKJ-TIM. Contohnya, pada tahun 1972/1973, dari anggaran kebudayaan Pemerintah DKI yang disetujui DPRD sebesar Rp 297 juta, Rp 264 juta disediakan untuk kegiatan PKJ-TIM. Selain itu, seniman mendapat kebebasan untuk berkegiatan dan mengekspresikan karyanya di TIM. Ninis mengungkapkan bahwa TIM saat itu sungguh merupakan laboratorium untuk pembelajaran pelaku seni itu sendiri. Laboratorium maksudnya adalah mahasiswa IKJ menjadikan TIM sebagai tempat menimba ilmu dan praktik kesenian. Mahasiswa tiap fakultas mendapat kesempatan untuk memakai TIM untuk pameran atau pertunjukan setiap enam bulan sekali. Mereka juga diwajibkan untuk menonton pertunjukan berbagai bidang seni di TIM dan membuat resume mengenai pertunjukan tersebut.

TIM disebut sebagai Pusat Kesenian Jakarta karena DKJ yang saat itu masih menjadi pengelola TIM tidak ikut campur dalam kegiatan-kegiatan kesenian. Kegiatan yang ada dibiarkan bertumbuh dan jika kegiatan tersebut baik, maka akan disponsori oleh DKJ untuk ditampilkan di PKJ-TIM. Seleksi dilakukan terhadap kegiatan kesenian yang bermutu di PKJ-TIM agar masyarakat menganggap bahwa pertunjukan yang disponsori DKJ dan dapat pentas di PKJ-TIM adalah kegiatan yang baik (Sukarman, 1983).

Jumlah kegiatan dan pengunjung TIM meningkat pada dua tahun pertama, tapi kemudian mulai menurun sejak 1971 (Rosidi, 1974). DKJ pun meninjau kembali pedoman dasarnya dan memasukkan kegiatan pembinaan apresiasi seni bagi masyarakat di tahun 1973. Minat terhadap pertunjukan drama di kalangan remaja pun meningkat dengan bertambahnya jumlah penonton serta tumbuhnya grup-grup teater remaja.

Selama tahun 1970, TIM menjadi model untuk pendirian pusat seni dan budaya lokal di kota-kota besar lain di Indonesia, seperti Taman Werdhi Budaya Art Centre di Bali yang didirikan tahun 1976, Taman Budaya Jawa Tengah (TBJT) Solo tahun 1979, dan Taman Budaya Yogyakarta (TBY) tahun 1980 (Hatley, 1994). TIM menentukan dirinya sebagai tempat pertunjukan nasional. Sementara itu, pusat-pusat kebudayaan adalah tempat yang dikelola negara di tingkat provinsi serta menjadi representasi bangsa dan provinsi (Jones, 2015).

Pada masa pemerintahan Ali Sadikin, DKJ dan AJ bekerja sama dengan Provinsi DKI Jakarta dan memiliki hubungan kerja yang baik. Namun, setelah Ali Sadikin pensiun pada tahun 1977, intervensi Pemprov DKI Jakarta meningkat sehingga menimbulkan ketegangan antara Provinsi DKI Jakarta dan kedua lembaga, yaitu AJ dan DKJ. Pada periode 1980, TIM mengalami kemerosotan dengan masuknya intervensi Pemprov DKI Jakarta ke TIM yang mempengaruhi seniman dalam berkarya (Jones, 2015).

Periode tahun 1980-an dan 1990-an ketika terjadi penurunan, TIM membuka diri terhadap usaha-usaha komersial seperti bioskop, toko kerajinan, dan manajemennya semakin berupaya menarik modal swasta (Jones, 2015). Zulkin (1996) mengemukakan salah satu penyebab kemerosotan ruang-ruang publik adalah ketidakmampuan atau keeng- 
ganan pemerintah kota untuk merawat dan mendanai ruang publik sehingga berada pada ruang komersial swasta (Barker, 2000).

Pada 22 Agustus 1989, didirikan Yayasan Kesenian Jakarta (YKJ) oleh Gubernur Wiyogo Atmodarminto. YKJ yang melibatkan potensi swasta dibentuk untuk membantu gubernur dalam mencari dana bagi pengelolaan TIM dan IKJ serta membiayai program-program yang dibuat oleh DKJ (Alisjahbana et al., 1993). Pembentukan yayasan yang menaungi PKJ-TIM untuk menghimpun dana itu dilakukan karena pemerintah tidak dapat menopang semua pembiayaan kegiatan kesenian. YKJ pun menjadi pengelola dua lembaga tersebut (Murgiyanto, 1994). YKJ kemudian bubar tahun 1998. Penyebabnya adalah krisis moneter, pimpinan yang meninggal, dan tidak bertemunya kesepakatan antara Pemerintah DKI dan yayasan itu sendiri. Dana abadi YKJ kemudian dihibahkan ke Insitut Kesenian Jakarta. Kemudian, tahun 2004 ditetapkanlah Persetujuan Gubernur Provinsi DKI Jakarta atas pengunduran diri Ketua dan seluruh anggota Pengurus Yayasan Kesenian Jakarta (Keputusan Gubernur Provinsi DKI Jakarta Nomor 758, 2004).

Sementara itu, penggunaan istilah pimpinan PKJ-TIM berganti-ganti hingga akhirnya konsisten menjadi Kepala Badan Pengelola (BP) di tahun 2005 pada masa pimpinan Drs. Teguh Widodo. Seniman dan karyawan BP memiliki hubungan yang dekat karena lingkungan kerja yang mendukung. Sistem pertunjukan yang merupakan kerjasama mengharuskan BP ikut terjun dalam produksi pertunjukan. Hal itu membuat seniman dan BP memiliki tujuan yang sama, yaitu keberhasilan pertunjukan dan penonton banyak.

Pada masa kepemimpinan Gubernur Basuki Tjahaja Purnama tahun 2015, pengelolaan TIM mengalami transisi lagi, dari Badan Pengelola menjadi Unit Pengelola (UP) yang dilaksanakan oleh Pegawai Negeri Sipil (PNS). Organisasi dan tata kerja Badan Pengelola PKJ-TIM tidak lagi sesuai dengan ketentuan peraturan perundang-undangan dan kebutu- han (Peraturan Gubernur Provinsi DKI Jakarta Nomor 109, 2014). Seniman merasa dialog antara pengelola dan seniman menjadi kurang karena dialog dengan UP hanya sebatas pembahasan formal. Seniman tidak lagi leluasa untuk nongkrong di TIM karena petugas-petugas keamanan TIM diambil dari aparat yang tidak dikenal seniman. Bahkan, Joni, seniman teater, mengakui bahwa ia pernah dilarang berkesenian ketika sedang latihan di plaza depan Teater Kecil oleh petugas keamanan. Sebelumnya, ia tidak pernah bermasalah untuk melakukan segala kegiatan kesenian di TIM. Perhatian gubernur terhadap pusat kesenian pun dirasakan tidak maksimal, ditandai dengan dana untuk TIM yang semakin berkurang.

Bagi Ninis, seniman tari, hubungan antarlembaga di TIM kini tidak lagi menjadi satu kesatuan, sehingga memperjuangkan program dan dana tidak lagi menjadi keperluan bersama. Hal tersebut bisa saja tidak disengaja karena ingin melakukan pengetatan birokrasi. Lebih lanjut, ia mengatakan bahwa perkembangan lembaga di TIM tidak menghasilkan regenerasi yang mengenal sejarah TIM dengan baik.

Secara umum, evolusi komunitas melibatkan penyesuaian yang berkelanjutan antara lokalitas dan institusi kekuatan supralokal. Semakin tinggi tekanan yang diberikan oleh institusi supralokal kepada lokalitas, respon dari komunitas cenderung akan melawan. Sebaliknya, jika tekanannya semakin rendah, ada kemungkinan terbentuknya kerja sama di antara mereka (Leeds, 1973). Joni dan Gerry (seniman film) mempersoalkan, jika pihak TIM mengatakan bahwa mereka melibatkan seniman, maka perlu dipertanyakan seniman mana yang diajak berdiskusi. Adanya seniman yang mempersoalkan kebijakan UP bagi Gerry merupakan bukti bahwa kemungkinan mereka tidak puas sebab tidak diajak dalam membuat kebijakan TIM.

“Kalo dibilang, 'Nggak, kita ajak' siapa yang diajak? Apakah benar orangorang yang hidup matinya di TIM, atau orang-orang yang cuma menikmati aja kesempatan dalam kesempitan? Itu 
yang penting." (Wawancara dengan Gerry, tanggal 17 Mei 2019).

Joni memaparkan bahwa kini seniman memiliki kepentingan yang berbeda-beda sehingga mereka tidak lagi bersatu untuk menyuarakan pendapatnya. Ninis dan Gatot (seniman teater) mengemukakan bahwa aspirasi seniman tersebut dapat disampaikan melalui surat atau diskusi. Walaupun begitu, seniman tetap tidak berdaya dalam kebijakan yang diterapkan di TIM. Protes seniman mengenai bantuan pendanaan pun tidak ditanggapi oleh pemerintah.

\begin{abstract}
"Mulai dari diskusi, kemudian mengirimkan delegasi ke Pemprov DKI untuk ada dialog, dan juga melalui surat itu surat imbauan maupun surat protes. Tetapi keputusan Pemprov DKI tetap, bahwa seniman harus bisa mencari dana sendiri. Itu yang terjadi sekarang."

(Wawancara dengan Gatot, tanggal 12 Februari 2019).
\end{abstract}

Aspirasi seniman juga disampaikan dalam bentuk karya melalui kreativitas bidang seni masing-masing, misalnya puisi.

Kepercayaan dan dukungan Pemerintah DKI Jakarta pada masa Gubernur Ali Sadikin membuat TIM dapat tumbuh sebagai barometer kesenian nasional. Selain itu, TIM juga menjadi model pendirian pusat kebudayaan di kota-kota besar lainnya. Dengan peluang manajerial yang luas, para seniman di DKJ sebagai pengelola TIM cukup jeli untuk mengatasi persoalan yang muncul dalam perkembangan TIM. Salah satunya adalah membuat kegiatan apresiasi seni bagi masyarakat untuk menjaga jumlah pengunjung yang dianggap sebagai indikator bagi kejayaan pusat kesenian itu.

Masuknya pengelolaan swasta membuat performa TIM sebagai pusat kesenian Jakarta dan nasional dari satu sisi dipandang surut. Namun, di sisi lain tedapat perkembangan-perkembangan juga, meskipun itu tidak lagi di bawah kendali seniman.

Pengelolaan TIM di bawah birokrasi pemerintah daerah dirasakan para informan tidak lagi melibatkan seniman. Tidak dilibatkannya seniman dalam pengelolaan TIM menimbulkan kendala-kendala untuk berkesenian. Kendala tersebut adalah (1) tidak leluasa dalam berkarya, (2) keterbatasan dana pertunjukan untuk seniman, (3) ada aturan yang membebani, hingga (4) kebijakan yang tidak didasarkan sudut pandang seni atau sejarah TIM sendiri. Pengelolaan di bawah UP tersebut mengurangi peranan seniman sehingga mereka tidak lagi mengikuti perkembangan TIM. Walaupun begitu, Unit Pengelola PKJ-TIM merasa bahwa mereka tetap melibatkan seniman dan mendengarkan aspirasi mereka.

\section{Keadaan Fisik Taman Ismail Marzuki}

Pembangunan pertama TIM dimulai pada pertengahan Juni 1968. Pemerintah DKI menunjuk Ir. Tjong Pragantha untuk pergi ke Hawaii guna mempelajari kompleks bangunan kesenian di sana serta survei ke berbagai daerah di Indonesia. Selain itu, Ir. Tjong juga berdiskusi dengan para arsitek ITB dan berdiskusi dengan kalangan seniman (Yusra, 1994). Proyek tahap utama pembangunan TIM memakan biaya sekitar Rp 90 juta rupiah (Hadimadja, 1992).

Pembangunan pada tahun 2013 di bawah kepemimpinan Gubernur Joko Widodo ditujukan untuk revitalisasi IKJ. Revitalisasi kemudian dilanjutkan Gubernur Djarot di tahun 2017 yang berfokus pada perbaikan Teater Jakarta, Graha Bhakti Budaya, kantin, dan plaza pada tahun 2017 (Windarto, 2017). Pada peresmian revitalisasi tanggal 12 Oktober 2017, patung Ismail Marzuki yang terletak di gerbang masuk dipindahkan ke depan Teater Jakarta (Pelita Jakarta, 2017). Padahal landmark PKJ-TIM buah karya seniman Arsono tahun 1984 itu sudah terletak di dekat pintu gerbang TIM sejak tahun 1985. Hal itu menimbulkan kontroversi di kalangan seniman, sehingga Gubernur Anies Baswedan memutuskan untuk mengembalikan patung yang telah ada sejak tahun 1985 itu ke tempat semula tanggal 14 Februari 2018 (Hartono, 2018).

Pada hari ulang tahun TIM ke-50 pada tanggal 10 November 2018, Pemprov DKI mencanangkan Rencana Besar Revitalisasi PKJ- 
TIM. Gubernur Anies Baswedan memaparkan bahwa revitalisasi bertujuan untuk memperbaiki ekosistem berkesenian yang berkualitas, mewujudkan masyarakat Jakarta yang berbudaya, serta menjadikan Jakarta Kota Budaya yang terkemuka di mata dunia (Indikatornews, 2018). Revitalisasi ini merupakan pembangunan yang lebih masif dari yang sebelumnya dan merupakan upaya untuk membuat TIM bangkit kembali seperti awal mula dibangun. Revitalisasi yang dilakukan di TIM tidak hanya secara fisik, melainkan juga kelembagaan (Nailufar, 2018). Oleh karena itu, Dewan Kesenian Jakarta dan Akademi Jakarta pun direstrukturasi.

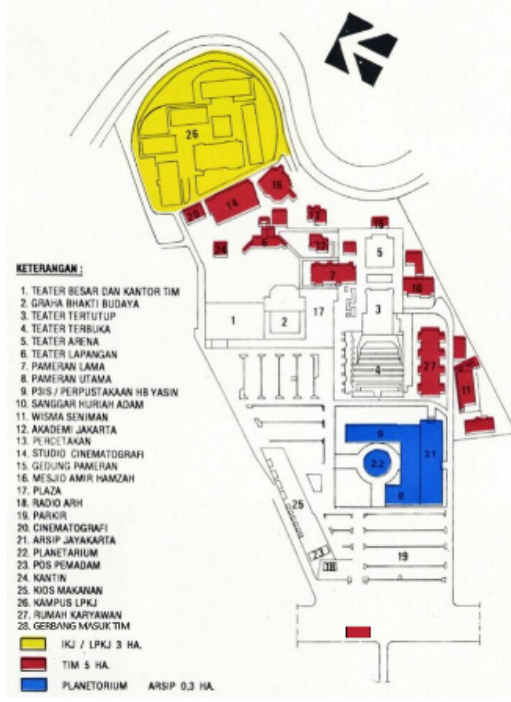

Gambar 1. Denah TIM (1993) Sumber: Alisjahbana, dkk. (1993) dari Arsip Dewan Kesenian Jakarta

Pada perkembangannya, bangunan-bangunan di TIM mengalami pembongkaran. Namun, ada pula bangunan-bangunan yang dibangun di masa lalu yang masih bertahan hingga sekarang.

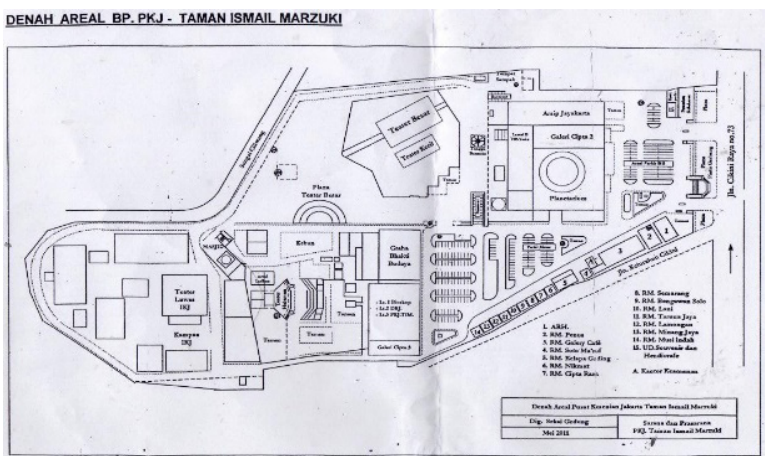

Gambar 2. Denah TIM (2011) Sumber: Arsip UP PKJ-TIM (2019)

\begin{tabular}{|c|c|c|}
\hline Sarana & $\begin{array}{l}\text { Waktu di- } \\
\text { dirikan }\end{array}$ & Waktu berubah \\
\hline \multicolumn{3}{|c|}{ Pertunjukan } \\
\hline \multirow{2}{*}{$\begin{array}{l}\text { Teater Tertu- } \\
\text { tup }\end{array}$} & 1968 & 1991: direnovasi \\
\hline & & $\begin{array}{l}\text { 1995-1996: } \\
\text { dirobohkan }\end{array}$ \\
\hline $\begin{array}{l}\text { Teater Ter- } \\
\text { buka }\end{array}$ & 1968 & $\begin{array}{l}\text { 1995-1996: } \\
\text { dirobohkan }\end{array}$ \\
\hline \multirow[t]{2}{*}{ Teater Arena } & 1968 & $\begin{array}{l}\text { 1972: dibangun } \\
\text { kembali karena } \\
\text { kebakaran }\end{array}$ \\
\hline & & $\begin{array}{l}\text { 1995-1996: } \\
\text { dirobohkan }\end{array}$ \\
\hline Teater Besar & 1968 & $\begin{array}{l}\text { 1988: direstorasi } \\
\text { untuk dihubung- } \\
\text { kan dengan } \\
\text { GBB }\end{array}$ \\
\hline $\begin{array}{l}\text { Graha Bhakti } \\
\text { Budaya } \\
(\mathrm{GBB})\end{array}$ & 1983 & 2017: renovasi \\
\hline \multirow[t]{2}{*}{ Teater Jakarta } & $1996-2010$ & $\begin{array}{l}\text { 1998-2001: } \\
\text { pembangunan } \\
\text { terhenti }\end{array}$ \\
\hline & & 2017: renovasi \\
\hline Teater Kecil & 2003 & \\
\hline \multicolumn{3}{|l|}{ Pameran } \\
\hline Galeri Cipta I & 1968 & $\begin{array}{l}\text { 1995-1996: } \\
\text { dirobohkan }\end{array}$ \\
\hline \multicolumn{3}{|l|}{$\begin{array}{l}\text { *Galeri Cipta } \\
\text { II }\end{array}$} \\
\hline \multicolumn{3}{|l|}{$\begin{array}{l}\text { *Galeri Cipta } \\
\text { III }\end{array}$} \\
\hline \multicolumn{3}{|l|}{ Latihan } \\
\hline $\begin{array}{l}\text { Ruang Tari } \\
\text { Huriah Adam }\end{array}$ & 1968 & $\begin{array}{l}\text { 1995-1996: } \\
\text { dirobohkan }\end{array}$ \\
\hline $\begin{array}{l}\text { Teater Hala- } \\
\text { man }\end{array}$ & 1968 & $\begin{array}{l}\text { 2013: diroboh- } \\
\text { kan }\end{array}$ \\
\hline Sanggar Baru & 1968 & $\begin{array}{l}\text { 2013: diroboh- } \\
\text { kan }\end{array}$ \\
\hline \multicolumn{3}{|l|}{ Bersosialisasi } \\
\hline Wisma Seni & 1968 & $\begin{array}{l}\text { 1995-1996: } \\
\text { dirobohkan }\end{array}$ \\
\hline $\begin{array}{l}\text { *Kantin Dewi } \\
\text { Indah }\end{array}$ & & \\
\hline
\end{tabular}




\begin{tabular}{l}
\hline Pendidikan \\
\hline Lembaga 1970 \\
Pendidikan \\
Kesenian \\
Jakarta \\
*belum/tidak ada informasi \\
Tabel 1. Perubahan Fisik Taman Ismail Marzuki tahun \\
1968-2018 Sumber: Tabel diolah oleh peneliti
\end{tabular}

Sarana yang tertera pada tabel di atas adalah sarana-sarana yang menunjang seniman dalam melakukan kegiatan seni, pendidikan, dan sosialisasi. Sesuai yang terlihat pada denah dan tabel, TIM mengalami berbagai perubahan fisik dalam masa yang berbeda. Kantin Dewi Indah tidak terdapat di dalam denah resmi, namun peneliti tambahkan pada Tabel 1. tersebut berdasarkan hasil wawancara. Kantin Dewi Indah yang dulunya merupakan kantin utama tempat seniman berkumpul, kemudian digantikan oleh 13 kantin yang letaknya berjejer (lihat Gambar 2.).

Perubahan fisik TIM yang sangat terlihat adalah ketika pengelolaan swasta masuk ke TIM pada tahun 1989 dan membongkar beberapa bangunan di sekitar tahun 1995-1996. Bangunan tersebut adalah Teater Terbuka, Teater Tertutup, Ruang Pameran Lama (Galeri Cipta I), Ruang Tari Huriah Adam, rumah karyawan, dan Wisma Seni yang dibongkar untuk pembangunan gedung yang lebih modern, yaitu Teater Jakarta dan Teater Kecil. Pembangunan tersebut memakan waktu yang cukup lama, yaitu selama 14 tahun dan sempat terhenti tiga tahun karena adanya krisis moneter. Akibatnya, seniman dan PKJ-TIM mengalami kerugian karena kegiatan dalam kurun waktu tersebut menjadi tidak maksimal. Kemudian, pada tahun 2013 juga terjadi pembongkaran pada Sanggar Baru dan Teater Halaman yang biasa menjadi tempat latihan juga Masjid Amir Hamzah untuk pengembangan kampus IKJ. Lokasi bekas bangunan tersebut berdiri kini menjadi lahan parkir kampus IKJ.

Agung, seorang perupa, mengatakan bahwa seniman daerah yang ingin pentas di TIM kebingungan karena tempat latihan dan tempat menginap yang tidak lagi ada. Joni memaparkan bahwa kreativitas dan aktivitas seniman terganggu dengan dibongkarnya tempat latihan, sehingga seniman mulai meninggalkan TIM. Selama ini, para seniman memakai tempat latihan yang terbatas, bergantian dengan pelaku seni yang lain. Ninis mengungkapkan bahwa TIM kehilangan gedung-gedung yang diperlukan untuk melengkapi sebuah pusat kesenian, baik ruang latihan maupun pertunjukan.

"Kita kehilangan ruang latihan. Dulu ada ruang latihan yang namanya Teater Huriah Adam, lalu ada di belakangnya itu ada ruang-ruang kecil gitu yang bisa dipakai latihan teater, lalu ada halamannya juga rumput yang bisa latihan di belakang. Sekarang udah hilang itu semuanya, ya. Sehingga yang terjadi anak-anak sekarang latihan ya di mana namanya di plaza depan, depannya ini ya depannya gedung bioskop atau GBB ya kan." (Wawancara dengan Ninis, tanggal 28 Juni 2019).

Gerry pun menyayangkan pembangunan IKJ yang kualitasnya tidak lebih baik daripada bangunan lama. Menurutnya, pembangunan di IKJ dan TIM seharusnya didampingi oleh orang-orang seni yang memahami kebutuhan bidang seni terkait, contohnya film. Heri, anggota DKJ, mengatakan hal senada. Bagi Heri, seharusnya DKJ dilibatkan dalam hal perancangan gedung sehingga sesuai dengan kebutuhan untuk berkesenian.

Ninis mengungkapkan bahwa seniman-seniman besar tidak lagi mempermasalahkan jika tidak bisa pentas di TIM karena masih ada alternatif gedung pertunjukan lainnya. Di tahun 2000-an TIM mulai surut seiring munculnya pusat-pusat seni budaya lain (Khoiri, 2015). Selain itu, di tahun 2005 mulai muncul galerigaleri seni komersial atau galeri independen. Alternatif tempat-tempat lain yang dimaksud, di antaranya adalah Komunitas Salihara di Pasar Minggu, Ciputra Artpreneur di Kuningan, Taman Mini Indonesia Indah, kedutaan asing, dan lain-lain. 
Salah satu ciri ruang publik yang bisa berfungsi optimal untuk kegiatan publik, baik individu maupun kelompok adalah memiliki lokasi yang strategis dan akses yang baik (Carr et al., 1992). Menurut pemaparan Ninis, untuk sebuah festival terutama internasional, TIM sebetulnya memiliki potensi yang besar. Hal itu karena di dalam satu tempat terdapat gedung-gedung pertunjukan, ruang pameran, area yang luas, serta merupakan lokasi yang strategis di tengah kota dengan keberadaan coffee shop, bar, dan hotel di sekitarnya. Tetapi, sangat disayangkan karena para seniman sependapat bahwa fasilitas TIM sudah tertinggal. Ninis yang berpengalaman dengan festival internasional sering kesulitan jika mengadakan pertunjukan di TIM, sehingga harus menyewa alat dari luar TIM. Bagi Ninis, gedung pertunjukan dan pameran di TIM tidak harus mewah, asalkan memiliki fasilitas-fasilitas yang memenuhi syarat.

Pada awal dibangunnya TIM, ruang-ruang yang disediakan oleh pemerintah disesuaikan dengan masukan dan kebutuhan para seniman. Ruang tersebut di antaranya adalah ruang latihan, pendidikan, pertunjukan, bersosialisasi, dan pameran sehingga dapat memaksimalkan seniman dalam memproduksi seni. Mereka pun dapat dengan mudah berkumpul dan berinteraksi dengan seniman berbagai bidang di TIM. Ketika pengelolaan berada di bawah swasta pun, seniman diajak diskusi secara terbuka dalam rencana pembangunan. Misalnya ketika pembongkaran beberapa bangunan untuk membangun Teater Jakarta dan Teater Kecil. Walaupun terjadi perdebatan dan pembongkaran tetap dilakukan, namun seniman menjadi bagian dari perencanaannya.

Para seniman menyayangkan bahwa tempat mereka berekspresi dibongkar tanpa memperhatikan apa yang menjadi kebutuhan seniman. Bagi mereka, bangunan-bangunan yang ada sebelumnya sudah memadai untuk mereka berkegiatan seni.

Kendala-kendala yang dirasakan seniman dari segi fisik, yakni (1) kurangnya tempat latihan, (2) fasilitas gedung pertunjukan tidak lengkap dan kurang memadai, (3) gedung pertunjukan terbatas, (4) TIM tidak lagi menjadi laboratorium IKJ, dan (5) pembangunan tidak didasarkan sudut pandang seni.

Revitalisasi diharapkan pemerintah menjadi jawaban atas keresahan para seniman. Meskipun begitu, para seniman belum meyakini revitalisasi akan mengembalikan TIM seperti semula, sebagai tempat seniman leluasa mempersiapkan dan mempertunjukkan kesenian mereka. Oleh karena itu, harapan seniman, revitalisasi yang dilakukan tidak hanya berupa fisik, melainkan juga kebijakan yang memperhatikan seniman.

\section{Sense of Place Seniman Taman Ismail Mar- zuki}

Sejak awal berdirinya TIM 50 tahun yang lalu hingga sekarang terdapat seniman-seniman yang masih berkegiatan di TIM. Di antara keenam seniman yang menjadi informan dalam penelitian ini, Joni merupakan yang paling lama berkesenian di TIM, yaitu sejak tahun 1972. Setelah itu, disusul oleh Eka yang kuliah di IKJ sejak tahun 1973 dan Gatot tahun 1976. Ninis, Agung, dan Gerry mulai menapaki TIM pada tahun yang sama, yaitu 1977 saat mereka kuliah di IKJ. Masing-masing dari seniman tersebut memiliki sejarah panjang dalam bidang kesenian, baik di dalam maupun di luar Taman Ismail Marzuki.

Keenam seniman tersebut masing-masing memiliki kegiatan rutin di TIM, baik kegiatan seni maupun kegiatan lainnya. Kegiatan seni yang dimaksud di antaranya adalah latihan, pentas, dan pameran. Sementara itu, di antara kegiatan lainnya, terdapat kegiatan akademik karena semua informan seniman merupakan alumni IKJ yang kemudian menjadi dosen di lembaga pendidikan kesenian itu. Mereka juga aktif bergiat di luar TIM. Dua seniman, yaitu Joni dan Ninis pernah menjadi anggota Dewan Kesenian Jakarta, masing-masing di Komite Teater dan Komite Tari.

Di samping kegiatan formal berkesenian dan mengajar tentang seni di TIM, tempat ini juga 
menjadi pangkalan seniman-seniman itu untuk bergaul dengan sesamanya, baik dari kalangan TIM maupun dari luar TIM. Dulu, mereka biasa berkumpul di Kantin Dewi Indah dan beberapa warung lain yang tempatnya nyaman karena berada di bawah pohon ketapang, sehingga seniman dari berbagai bidang kesenian bisa berkumpul di sana hingga pagi. Selain warung-warung tersebut, ada pula Wisma Seni yang menjadi tempat menginap seniman berbagai daerah. Seniman juga bisa duduk-duduk di sekitar Teater Arena, Wisma Seni, Teater Tertutup, dan Ruang Tari Huriah Adam.

Sekarang ini, beberapa seniman terlihat sering berkumpul di bawah tempat baliho di luar gerbang TIM, di bawah pohon beringin depan Galeri Buku Bengkel Deklamasi, di bawah pohon beringin depan Galeri Cipta II, atau IKJ. Ninis dan Eka (66 tahun) mengakui bahwa mereka tidak lagi mengetahui seniman-seniman yang masih nongkrong di TIM karena mereka fokus berkegiatan di IKJ. Bagi para informan, tempat berkumpul seniman yang memadai diperlukan sebagai sarana bertukar pikiran. Tidak hanya sesama seniman, kegiatan berdiskusi juga dulu sering dilakukan antara dosen atau seniman dengan mahasiswa. Dari diskusi-diskusi sambil nongkrong tersebut, mahasiswa mendapat banyak ilmu dari pengalaman-pengalaman seniman yang tidak mereka dapatkan di perkuliahan. Perilaku kolektif di TIM pun perlahan hilang karena berkurangnya tempat untuk bersosialisasi. TIM saat ini hanya dijadikan sekadar tempat bekerja (pertunjukan, pameran, atau mengajar) karena seniman hanya fokus pada kegiatan seni yang ditekuni dan memiliki alternatif tempat pertunjukan dan berkumpul lainnya.

Salah satu kualitas utama dari sebuah ruang publik adalah bermakna (meaningful) karena adanya ikatan emosional antara ruang dengan kehidupan penggunanya (Carr et al., 1992, Darmawan, 2007). Seniman TIM memiliki pemaknaan berbeda-beda mengenai tempat berkesenian mereka selama puluhan tahun. Namun mereka sependapat bahwa sekarang tidak ada lagi bagian TIM yang penting untuk seniman, kecuali tempat pertunjukan dan pa- meran yang masih mereka perlukan.

Pada masa pemerintahan Gubernur Ali Sadikin, seniman merasa bebas untuk berkegiatan di TIM. Bang Ali memberikan seniman kebebasan mencipta dengan mempertaruhkan jabatannya sendiri, hal yang tidak pernah diberikan oleh para pejabat sesudahnya atau oleh pejabat lain di tempat lain di negara Indonesia (Rosidi, 2006). Bang Ali yang rutin berkunjung ke TIM selalu menyapa seniman sehingga membuat roh TIM menjadi hangat dan akrab.

Sekarang, seniman tidak lagi mengetahui perkembangan TIM karena kurangnya komunikasi dengan pengelola. Menurut Eka dan Gerry, perubahan bangunan memang membuat TIM menjadi modern, namun atmosfernya berbeda dan kurang hangat dibandingkan dengan TIM dahulu. Lebih lanjut Eka menuturkan bahwa gedung di TIM yang semakin megah tidak dibarengi dengan kehangatan roh kesenimanan.

Meskipun begitu, Agung dan Gerry tetap menganggap TIM sebagai rumah mereka. Bahkan, Gerry mengungkapkan keinginannya ketika wafat untuk dibawa ke TIM sebelum dimakamkan. TIM, bagi Joni, Eka, dan Gatot adalah tempat pertukaran ide-ide kreatif guna melestarikan seni serta mendidik dan mengapresiasi seniman. Joni dan Agung mengungkapkan bahwa dengan adanya perubahan di TIM, seniman harus siap dan menyesuaikan diri agar tidak tenggelam.

"Ya apa ya... Kadang-kadang saya sendiri juga gitu, mau menerima tapi dari dalem hati kecil saya nggak menerima, tapi ya gimana lagi gitu lho. Jadi sebetulnya saya mau protes kayak apa pun juga.. Mungkin kalo saya sendiri nggak akan digubris gitu lho." (Wawancara dengan Agung, tanggal 22 Februari 2019).

Menurut Gerry, sudah menjadi konsekuensi seniman untuk hidup dengan generasi-generasi baru sehingga seniman harus menyesuaikan karena itu tuntutan zaman. 
"Yang kayak gitu-gitu aku juga nggak tahu apakah aku egois atau nggak ya? Seperti menuntut nostalgia yang sebenarnya udah nggak ada, udah berubah, gitu. Atau kita memang harus ya udah ini konsekuensi nih. Ini yang ada sekarang, kita hidup dengan generasi-generasi baru, dengan cara berpikir baru, ya kita harus ikutin. Atau kita yang pergi." (Wawancara denga Gerry, tanggal 17 Mei 2019).

Oleh karena itu, seniman berharap rencana revitalisasi bukan hanya revitalisasi fisik saja. Mereka berharap TIM dapat berjaya kembali dengan memperhatikan kebutuhan seniman serta tetap berpedoman pada visi misi TIM sebagaimana dibangun Gubernur Ali Sadikin dahulu. Selain itu, dengan adanya perubahan ke arah modern, jangan sampai roh TIM sebagai pusat kesenian hilang. TIM perlu kembali aktif dalam mengadakan kegiatan seni.

TIM sebagai "rumah" dapat didefinisikan sebagai tempat seniman tumbuh, berkembang, diterima, dan ikut membentuk "rumah" tersebut. Keadaan seniman pada masa Ali Sadikin menunjukkan tingkat ketiga dari sense of place yang dipaparkan oleh Gussow dikutip Relph (1976), yaitu seniman memiliki keakraban yang mendalam dengan TIM. Rasa itu terkait dengan kebebasan mereka di TIM, mulai dari berkesenian, manajerial, hingga tidur di sana.

Sense of place dapat dipengaruhi oleh perilaku kolektif (Najafi dan Shariff, 2011). Hal itu ditunjukkan pada masa Gubernur Ali Sadikin karena seniman TIM bisa dengan mudahnya berkumpul dengan seniman daerah maupun internasional. Perilaku kolektif tersebut lambat laun hilang karena tempat untuk bersosialisasi menjadi kurang. Selain itu juga terdapat faktor dari perkembangan seniman yang tidak lagi tergantung pada TIM. Keadaan TIM sekarang melemahkan sense of place para seniman sehingga seniman hanya menjadikan TIM sebagai tempat bekerja (pertunjukan, pameran, atau mengajar). Perubahan yang terjadi setelah era Gubernur Ali Sadikin tidak hanya mengurangi peranan seniman sebagai pengelola pusat kesenian, tetapi juga mengubah perasaan subyektif mereka terhadap TIM.

\section{Simpulan}

Tulisan ini memperlihatkan tiga fase yang menunjukkan perubahan peranan seniman dan perubahan pada rasa keterikatan seniman terhadap TIM sebagai ruang berkesenian.

Pertama, fase Gubernur Ali Sadikin: kebebasan berkesenian dan manajerial yang diberikan Pemerintah DKI Jakarta membuat seniman menganggap TIM sebagai markas berkesenian. Keterikatan ini menumbuhkan semangat berkesenian dan mengoreksi kelemahan-kelemahan mereka sendiri sehingga TIM dapat tumbuh menjadi barometer kesenian nasional.

Kedua, fase pasca Gubernur Ali Sadikin: meningkatnya intervensi Pemprov DKI Jakarta. Dukungan pemerintah pun berkurang, sehingga melibatkan pengelolaan swasta untuk membiayai kegiatan kesenian di TIM. Sense of place seniman pun terganggu dan kegiatan berkesenian kurang optimal.

Ketiga, fase masuknya birokrat pemerintah daerah di TIM: peranan seniman mulai berkurang sehingga mereka tidak lagi mengikuti perkembangan TIM. TIM hanya dijadikan sekadar tempat untuk bekerja (pertunjukan, pameran, dan mengajar) karena seniman hanya fokus pada kegiatan seni yang ditekuni dan memiliki alternatif tempat lain untuk berkegiatan.

Penelitian ini menemukan faktor penting yang membuat seniman tidak melawan meskipun kecewa dengan perubahan status mereka, yaitu (1) tidak dilibatkannya seniman membuat mereka menyadari bahwa mereka tidak memiliki kekuatan, (2) adanya ruang-ruang seni alternatif di luar TIM, dan (3) seniman mulai terpecah-pecah karena perbedaan kepentingan. Sense of place yang mengikat seniman dengan TIM adalah (1) TIM adalah tempat mereka bekerja karena memberikan peluang berkesenian dan pendidikan), (2) tanggung jawab manajerial TIM, serta (3) interaksi sosial dengan sesama seniman. 
Kesimpulannya, penelitian ini menunjukkan bahwa untuk mengkaji sebuah tempat dan kehidupan yang berlangsung di dalamnya, seharusnya juga memperhatikan kaitannya dengan hal-hal lain di luar tempat itu. TIM sebagai lokus berkesenian bisa hidup, berkembang, dan bahkan surut karena ada hubungan supralokal dengan Pemerintah Provinsi DKI Jakarta juga hubungan ekstralokal dengan sesama seniman dan lembaga-lembaga kesenian lain, di tingkat lokal (Jakarta) dan nasional, bahkan dengan dunia internasional.

TIM sebagai salah satu pusat kesenian terbesar di Jakarta perlu dijaga eksistensinya sebagaimana tujuan awal didirikannya, yaitu sebagai sebuah tempat seniman untuk bekerja, menggelar karya, bertemu, dan bertukar pikiran. Suatu ruang publik yang disediakan dan dikelola oleh pemerintah, bila diubah hanya sesuai pemikiran pemerintah tetapi tidak menyertakan pengguna utamanya, lambat laun dapat mengurangi fungsinya dan akan menimbulkan kontroversi dari kalangan seniman yang mengerti seluk-beluk TIM. Skripsi ini dapat menjadi acuan bagi pengelola atau kelompok-kelompok yang berkepentingan di TIM untuk lebih memahami kesejarahan TIM.

Sebagai catatan tambahan, di dalam penelitian ini ditemukan bahwa data historis dari pengelola TIM sekarang (UP) mengenai TIM kurang lengkap. Ketidaklengkapan data UP selaku pengelola TIM mungkin disebabkan oleh tidak adanya serah terima pengelolaan dari BP ke UP. Jika peningkatan TIM tidak hanya di revitalisasi fisik, tetapi juga peningkatan profesionalitas manajerialnya, maka pengelolaan dan pengarsipan data sebaiknya diutamakan.

\section{Daftar Pustaka}

Alisjahbana, P., Murgiyanto, S., Said, S., Gondomono, T., Gondomono, dan Sriwibawa, S. (Eds.). (1993). Pusat Kesenian Jakarta Taman Ismail Marzuki. Jakarta: Yayasan Kesenian Jakarta.

Barker, C. (2000). Cultural Studies: Teori dan Praktik. Yogyakarta: Bentang.

Carr, S., Francis, M., Rivlin, L. G., dan Stone, A. M. (1992). Public Space. Cambridge: Cam- bridge University Press.

Dewi, C. S. (2017). Peran Taman Ismail Marzuki Terhadap Perkembangan Seni Rupa Kontemporer Indonesia: Kajian Peristiwa Pameran Seni Rupa Era 1970-an. Jurnal Seni Nasional Cikini, 2(2), 7-17.

Hadimadja, R. K. (1992), Bang Ali Demi Jakarta. Jakarta: Pustaka Sinar Harapan.

Hartono, Y. S. (2018). Patung Ismail Marzuki Kembali Dekat Gerbang TIM. Kabare.Id.

Hatley, B. (1994). Cultural Expression. Dalam H. Hill (Ed.), Indonesia's News Order: The Dynamic of Socio-Economic Transformation (pp. 216-266). Honolulu: University of Hawaii Press.

Indikatornews. (2018). Pencanangan Rencana Besar Revitalisasi Taman Ismail Marzuki. Indikatornews.Com. https://indikatornews.com/pencanangan-rencana-besar-revitalisasi-taman-ismail-marzuki/

Jones, T. (2015). Kebudayaan dan Kekuasaan di Indonesia: Kebijakan Budaya selama Abad ke-20 hingga Era Reformasi. Jakarta: Yayasan Pustaka Obor Indonesia.

Keputusan Gubernur Provinsi DKI Jakarta Nomor 758. , (2004).

Keputusan Gubernur Provinsi DKI Jakarta Nomor 790. , (2013).

Khoiri, I. (2015). Taman Ismail Marzuki, Nasibmu Kini. Kompas.Com. https://megapolitan. kompas.com/read/2015/01/13/23000411/Taman.\%09Ismail.\%09Marzuki.Nasibmu.Kini

Kustianingrum, D., Sukarya, A. K., Nugraha, R. A., dan Tyagarga, F. R. (2013). Fungsi dan Aktifitas Taman Ganesha Sebagai Ruang Publik di Kota Bandung. Jurnal Reka Karsa, 1(2), 1-14.

Leeds, A. (1973). Locality Power in Relation to Supralocal Power Institutions. Dalam A. Southall (Ed.), Urban Anthropology (pp. 15-41). New York: Oxford University Press.

Leirissa, R. Z. (1994). Ensiklopedi Tokoh Kebudayaan. Jakarta: CV Dwijaya Karya.

Low, S. M. (1996). Spatializing Culture: The Social Production and Social Construction of Public Space in Costa Rica. American Ethnologist, 23(4), 861-879.

Manurung, P. (2018). Kota untuk Semua: Ide Penataan Kota yang Komprehensif. Yogyakarta: ANDI.

Murgiyanto, S. (1994). Perjalanan Taman Ismail Marzuki. Dalam P. Alisjahbana, S. Murgi- 
yanto, S. Said, T. Gondomono, Gondomono, dan S. Sriwibawa (Eds.), 25 Tahun Pusat Kesenian Jakarta (pp. 66-75). Jakarta: Yayasan Kesenian Jakarta.

Nailufar, N. N. (2018). Dewan Kesenian Jakarta dan Akademi Jakarta akan Direstrukturasi. Kompas.com. https://megapolitan.kompas.com/ $\mathrm{read} / 2018 / 10 / 23 / 07065261 /$ dewan-kesenian-jakarta-dan-akademi-jakarta-akan-direstrukturisasi

Najafi, M., dan Shariff, M. K. B. M. (2011). The concept of place and sense of place in architectural studies. World Academy of Science, Engineering and Technology, 80(8), 11001106.

Nas, P. J. M. (2011). Cities Full of Symbols: A Theory of Urban Space and Culture. Leiden: Leiden University Press.

Pelita Jakarta. (2017). Patung Ismail Marzuki Tak Lagi Jadi Ikon TIM. Pelita Jakarta. https:// www.pelitajakarta.com/378/2017/10/15/patung-ismail-marzuki-tak- lagi-jadi-ikontim/

Peraturan Gubernur Provinsi DKI Jakarta Nomor 109. , (2014)

Peraturan Gubernur Provinsi DKI Jakarta Nomor 64. , (2006).

Raditya, M. H. B. (2016). Mengartikulasikan Ruang Publik dan Karya Seni. Mata Jendela, 4-13.

Relph, E. (1976). Place and Placelessness. London: Pion.

Rosidi, A. (1974). Taman Ismail Marzuki. Jakarta: PT Grafika Jaya.

Rosidi, A. (2006). Ali Sadikin dan Kesenian (B. Bujono, Ed.). Jakarta: IKJ Press bekerjasama dengan keluarga besar H. Ali Sadikin.

Scruton, R. (1987). Public Space and the Classical Vernacular. The Public Face of Architecture: Civic Culture and Public Spaces, 14-25, 5-16.

Shamai, S. (1991). Sense of Place: An Empirical Measurement. Geoforum, 22(3), 347-358.

Sukarman, M. (1983, November). Memperingati 15 Tahun Taman Ismail Marzuki.

Sunaryo, R. G., Soewarno, N., Ikaputra, dan Setiawan, B. (2010). Posisi Ruang Publik dalam Transformasi Konsepsi Urbanitas Kota Indonesia. Serap, 1-8.

Windarto. (2017). Djarot Resmikan Revitalisasi Taman Ismail Marzuki. Megapolitan Smart Magazine. https://jakrev.com/megapolitan/ birokrasi/djarot-resmikan-revitalisasi-taman-ismail-marzuki/

Yudoseputro, W. (1994). Institut Kesenian Jakarta: Menatap Hari Depan Kesenian Indonesia. Dalam P. Alisjahbana, S. Murgiyanto, S. Said, T. Gondomono, Gondomono, dan S. Sriwibawa (Eds.), 25 Tahun Pusat Kesenian Jakarta (pp. 76-86). Jakarta: Yayasan Kesenian Jakarta.

Yusra, A. (1994). Berdirinya Pusat Kesenian Jakarta. Dalam P. Alisjahbana, S. Murgiyanto, S. Said, T. Gondomono, Gondomono, dan S. Sriwibawa (Eds.), 25 Tahun Pusat Kesenian Jakarta (pp. 24-32). Jakarta: Yayasan Kesenian Jakarta. 